\title{
In Situ CT Tensile Testing of an Additively Manufactured and Heat-Treated Metastable B-Titanium Alloy (Ti-5Al-5Mo-5V-3Cr)
}

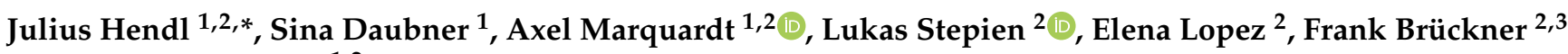 \\ and Christoph Leyens ${ }^{1,2}$
}

check for

updates

Citation: Hendl, J.; Daubner, S.; Marquardt, A.; Stepien, L.; Lopez, E.; Brückner, F.; Leyens, C. In Situ CT Tensile Testing of an Additively Manufactured and Heat-Treated Metastable B-Titanium Alloy (Ti-5Al-5Mo-5V-3Cr). Appl. Sci. 2021, 11, 9875. https://doi.org/10.3390/ app11219875

Academic Editor: Ricardo Branco

Received: 20 August 2021

Accepted: 18 October 2021

Published: 22 October 2021

Publisher's Note: MDPI stays neutral with regard to jurisdictional claims in published maps and institutional affiliations.

Copyright: (c) 2021 by the authors. Licensee MDPI, Basel, Switzerland. This article is an open access article distributed under the terms and conditions of the Creative Commons Attribution (CC BY) license (https:/ / creativecommons.org/licenses/by/ $4.0 /)$.
1 Institute of Materials Science, Technische Universität Dresden, Helmholtzstr. 7, 01069 Dresden, Germany; sina-daubner@gmx.de (S.D.); axel.marquardt@tu-dresden.de (A.M.); christoph.leyens@tu-dresden.de (C.L.)

2 Fraunhofer-Institute for Material and Beam Technology (IWS-Dresden), Winterbergstraße 28, 01069 Dresden, Germany; lukas.stepien@iws.fraunhofer.de (L.S.); elena.lopez@iws.fraunhofer.de (E.L.); frank.brueckner@iws.fraunhofer.de (F.B.)

3 Department of Engineering Sciences and Mathematics, Luleå University of Technology, 97187 Luleå, Sweden

* Correspondence: julius.hendl@tu-dresden.de

\begin{abstract}
Additive manufacturing has been considered a suitable process for developing highperformance parts of medical or aerospace industries. The electron beam powder bed fusion process, EB-PBF, is a powder bed fusion process carried out in a vacuum, in which the parts are melted using a highly focused electron beam. The material class of metastable $\beta$-titanium alloys, and especially Ti-5Al-5Mo-5V-3Cr, show great potential for use as small and highly complex load-bearing parts. Specimens were additively manufactured with optimised process parameters and different heat treatments used in order to create tailored mechanical properties. These heat-treated specimens were analysed with regard to their microstructure (SEM) and their mechanical strength (tensile testing). Furthermore, in situ tensile tests, using a Deben CT5000 and a YXLON ff35 industrial $\mu$-CT, were performed and failure-critical defects were detected, analysed and monitored. Experimental results indicate that, if EB-PBF-manufactured Ti-5553 is heat-treated differently, a variety of mechanical properties are possible. Regarding their fracture mechanisms, failure-critical defects can be detected at different stages of the tensile test and defect growth behaviour can be analysed.
\end{abstract}

Keywords: additive manufacturing; electron beam powder bed fusion; titanium alloy; processstructure-property relationship; industrial computer tomography; non-destructive-evaluation; in situ tensile testing; materials characterisation

\section{Introduction}

According to recent studies, environmental awareness has become a topic of huge interest, and is placed on a comparable level to social equity or education [1]. In order to reduce the carbon footprint of many moving vehicles (e.g., airplanes, cars or rockets) new approaches need to be considered. From a materials engineering point of view it is obvious that the field of lightweight construction still has much potential [2]. There are two main routes which can be followed in order to construct lighter parts. One is the redesign of parts using topology optimisation in order to calculate optimal material distribution and ultimately reduce their weight [3]. In order to build these highly complex parts conventional manufacturing methods can often not be used due to their design limitations or non-cost-effective production. Additive manufacturing (AM) methods can overcome many of these limitations due to their layer-by-layer process [4,5]. Furthermore, the effectivity could be increased by recycling the used powder multiple times, and therefore environmental impact as well as process waste can be minimised. Furthermore, costs for small badges or individual parts (e.g., implants) can be reduced due to the easy adaptability of the AM processes [6-8]. Using AM processes brings great challenges; one main problem is the appearance of inherent defects during the processes, such as a lack of fusion, non-melted 
powder, swelling or cracks [9]. Other challenges are the high investment costs, the high maintenance work and the residual stresses introduced in the process [6-8]. The other route to achieve lightweight construction is to substitute the material with a lighter and comparably strong material. Consequently, titanium and titanium alloys have gained increasing relevance [10]. The metastable $\beta$-alloy Ti-5Al-5Mo-5V-3Cr (Ti-5553) is used commercially as a material for the landing gear of the Boeing 787 Dreamliner. Ti-5553 shows a good combination between high mechanical strength and fatigue properties. When heat-treating Ti-5553 it can reach a yield strength (YS) of up to $1300 \mathrm{MPa}$ [11] and an ultimate tensile strength (UTS) of $1500 \mathrm{MPa}$ [12]. Other research has shown that by applying different heat treatments the maximum elongation and the overall fatigue properties can be significantly improved [11]. The difference between the metastable $\beta$-titanium alloys and the $\alpha+\beta$ alloys, of which the most widely used is Ti- $6 \mathrm{Al} 14 \mathrm{~V}$, is that the matrix and precipitation phases are the other way around $[13,14]$. Hence, Ti-5553 shows a bcc $\beta$-titanium matrix with good ductility and toughness, and an hcp $\alpha$-titanium precipitation. $\alpha$-titanium can be precipitated, depending on the respective temperature during the precipitation process, as primary, $\alpha_{p}$, or secondary, $\alpha_{s}$, alpha. These precipitations act as strengthening phases and can increase, depending on their size, shape and distribution, the mechanical strength significantly [15]. In the case of conventionally and AM-produced Ti-5553, quenching during the manufacturing process or a subsequent heat treatment can lead to the formation of the strength-reducing omega phase [16-19]. This can be excluded in the present work due to the prevailing process temperatures and the associated slow cooling rate $[13,20]$. If these are very fine grains, then they have the greatest influence due to the formation of dislocation barriers at $\alpha-\beta$ interfaces. If these grow larger, they can further improve the elongation properties due to slip and shear processes in large primary $\alpha$ precipitations [21,22]. Furthermore, titanium is also very resistant to corrosion and lightweight [13]. When combining AM with new advanced materials as well as with new approaches, such as topology optimisation, in order to design lightweight parts, a significant amount of weight can be saved without losing any stability and function ability [2,5]. In this work, Ti-5553 alloy is manufactured via the electron beam powder bed fusion (EB-PBF) process, and subsequently heat-treated in two different ways to obtain tailor-made properties. The specimens used were built using an optimised set of process parameters with a line energy of $E_{L}=600 \mathrm{~J} / \mathrm{m}$ [20]. The heat-treated specimens were further investigated regarding their density and mechanical behaviour. A general concern about AM parts are the processinherent defects and inhomogeneities which reduce the lifetime of these parts [23]. These defects are caused by non-optimised process parameters or small irregularities. In order to be able to determine the component quality, non-destructive material testing is essential. By using an industrial micro-focus computer tomograph ( $\mu-\mathrm{CT})$, defects inside the used Ti-5553 samples were analysed and afterwards categorised with regard to their respective size, morphology and distribution. However, it should be mentioned that defects can be classified using the above-mentioned categories but still have different effects on the mechanical behaviour. By performing a tensile test in situ inside a $\mu$-CT, failure-critical defects can be located and tracked until the part breaks.

Currently, the research on AM parts in general is not at a stage that sound predictions concerning the influence of defects can be made. In this research, a groundwork for in situ tensile testing and defect tracking was formed, on which basis further investigations on the influence of defects on AM parts can be made.

\section{Materials and Methods}

\section{1. $T i-5553$}

The titanium alloy Ti-5553 is a metastable $\beta$-titanium alloy. These alloys can reach very high mechanical strengths compared to other titanium alloys. A comparison between different titanium (alloys) can be seen in Table 1. In addition to higher mechanical strength, metastable $\beta$-alloys show increased ductility, fracture toughness and cold deformation behaviour compared to the most used Ti alloy, Ti-6Al4V [24-26]. These properties are 
attributed to the ductile $\beta$-matrix and the strengthening phase of $\alpha$ precipitations [14]. Furthermore, it must be mentioned that the powder bed temperatures, required in the EB-PBF process, can be lowered to $660 \pm 12{ }^{\circ} \mathrm{C}$ compared to the other materials.

Table 1. Mechanical properties of different Ti alloys [13,27].

\begin{tabular}{ccccc}
\hline Alloy & $\mathbf{T}_{\boldsymbol{\beta}}$ in ${ }^{\circ} \mathbf{C}$ & YS in MPa & UTS in MPa & Young Modulus in GPa \\
\hline Pure titanium & 882 & 140 & $100-145$ & 110 \\
Ti-6Al4V & 995 & $800-1100$ & $900-1200$ & $110-140$ \\
Ti-10V-2Fe-3Al & 800 & $1000-1200$ & $1000-1400$ & 110 \\
Ti-5Mo-5V-5Al-3Cr & 845 & 1250 & 1400 & 110 \\
\hline
\end{tabular}

In Figure 1 an EB-PBF-manufactured Ti-5553 microstructure can be seen. The $\beta$-matrix shows a bcc structure compared to the hcp-structured $\alpha$-phase [13]. Materials with bcc structures have more active slip planes and are much more deformable compared to hcp structures [28].

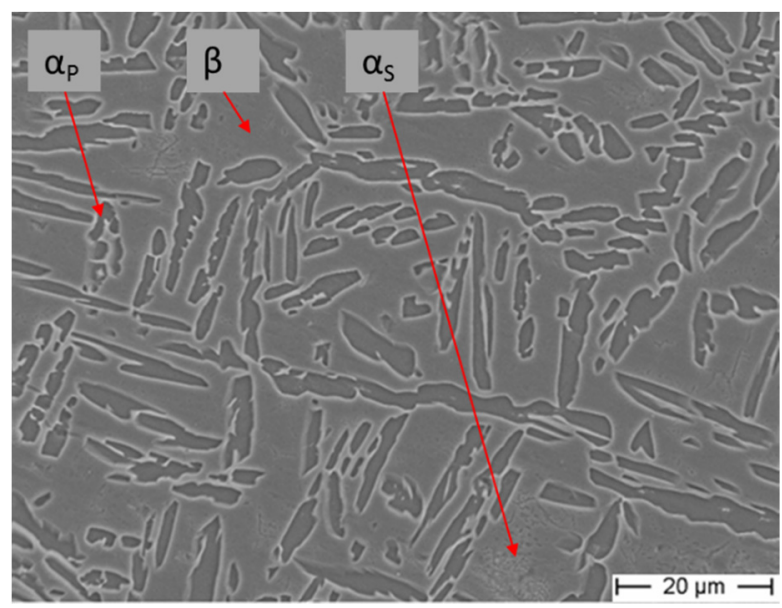

Figure 1. As-built microstructure of an EB-PBF Ti-5553 using $E_{L}=600 \mathrm{~J} / \mathrm{m}$.

The microstructure constituent that can most strongly influence the mechanical properties is the $\alpha$ precipitations. These can be precipitated, depending on the temperature, as primary $\alpha_{\mathrm{p}}\left(\mathrm{T}>600{ }^{\circ} \mathrm{C}\right)$ or secondary $\alpha_{\mathrm{s}}\left(\mathrm{T}<600^{\circ} \mathrm{C}\right)$ phases [13]. $\alpha_{\mathrm{p}}$ precipitations are usually lager in size, compared to $\alpha_{s}$, due to their increased exposure times at high temperatures and, therefore, enhanced diffusion time [15]. Firstly, these precipitate along grain boundaries and afterwards inside grains. $\alpha_{s}$ precipitate from a nucleation point and eventually form Wittmannstätt microstructures. These precipitates are very small and have a needle-like shape. Due to the decreased times at high temperature the growth is severely limited. If the Ti-5553 alloy is kept at a high temperature for a longer time, these precipitates grow and rearrange themselves into a triangular shape [29]. Large and dense precipitations (mainly $\alpha_{p}$ ) along grain boundaries lead to a decreased fracture toughness and deteriorate the mechanical properties [14]. Large precipitations can deform under slipping and shearing stress $[11,15]$. Furthermore, Huang et al. has shown that $\alpha_{\mathrm{s}}$ precipitations of 5-10 $\mu \mathrm{m}$ can also deform under a twining mechanism [21]. Overall, it can be said that large $\alpha_{p}$ precipitations strengthen the material but decrease the ductility. Due to the small size of the $\alpha_{\mathrm{w}}$ precipitates, dislocations can be favourably accumulated, which can significantly increase the material's strength [30,31]. By using different heat treatments and therefore changing the fractions, morphology and size of phases, tailor-made properties can be achieved [15]. A dense population of $\alpha$ precipitations directly affects the stability of the $\beta$-matrix. The $\beta$ stabilising elements (Mo, $\mathrm{V}$ and $\mathrm{Cr}$ ) diffuse into the matrix, and therefore the concentration of these is enriched there [15]. For the Ti-5553 alloy, two main heat treatments are currently used. The solution-treated and aged (STA) treatment is used 
for high mechanical strength and the beta-annealed, slow-cooled and aged (BASCA) treatment is used for maximum fatigue and fracture toughness performance [32]. The STA heat treatment involves a solution step at $790{ }^{\circ} \mathrm{C}$ (heating rate of $10 \mathrm{~K} / \mathrm{min}$ ) for $1 \mathrm{~h}$ followed by an air quench down to room temperature and an ageing step at $500{ }^{\circ} \mathrm{C}$ (heating rate of $10 \mathrm{~K} / \mathrm{min}$ ) for $1 \mathrm{~h}$. In comparison, the BASCA heat treatment involves an annealing step at $890{ }^{\circ} \mathrm{C}$ (heating rate $10 \mathrm{~K} / \mathrm{min}$ ) for $1.5 \mathrm{~h}$ followed by an oven cooling of $2 \mathrm{~K} / \mathrm{min}$ down to the aging step at $600{ }^{\circ} \mathrm{C}$ for $8 \mathrm{~h}$.

\section{2. $E B-P B F$}

EB-PBF is an AM process, which belongs to the powder bed fusion (PBF) processes. AM, and especially EB-PBF, is based on a cyclical process and consists of the following steps: lowering the building table-application of the powder-preheating-meltingreheating. How far the table is lowered at each step defines the layer thickness, which for the EB-PBF process can be between 50-200 $\mu \mathrm{m}$ [33] (in this study a layer thickness of $70 \mu \mathrm{m}$ was used). Powder is applied onto the previous layer, raked even and afterwards pre-heated using a highly defocused electron beam. The pre-heat prevents the powder from smoking and therefore enables a stable process. The main parameters to optimise in an EB-PBF process are scanning speed, beam current, hatch spacing and focus offset. In previous work, stable process parameters for manufacturing Ti-5553 in the used ARCAM A2X were found [20]. One foremost problem when utilising PBF is associated processinherent defects, which act as crack nucleation sites and tend to reduce the lifetime of AM parts. Depending on their origin, different defects are more or less critical [34]. Large, unregularly shaped defects such as those cause by lack of fusion, cracks, unmolten powder or delamination should be eliminated fully due to their negative impact on the respective mechanical properties $[23,35,36]$. Smaller, mostly round defects such as gas pores tend to be less important with regard to their impact [37]. The used specimens for the conventional and in situ samples were manufactured in two individual production runs. By using the same process parameters, it can be expected that the production runs will be comparable.

\subsection{Industrial Computer Tomography}

Industrial $\mu$-CT is a non-destructive investigation method where parts are scanned with $\mathrm{X}$-rays. During the CT process, high-energy X-ray radiation was emitted and directed onto the testing part. The part was mounted on a rotating manipulator. During the interaction between the X-rays and scanned part, a quantity of the radiation gets absorbed, and the radiation traversing the test part is collected by a detector, usually a CCD camera [38]. If defects and/or inhomogeneities are located inside the investigated part, the absorption at these locations is less comparable to the fully dense material. Hence, more radiation is detected and defects can be located via analysis software. For the presented research a voltage of $110 \mathrm{kV}$ and a current of $100 \mu \mathrm{A}$ were used, resulting in a voxel size of $9.27 \mu \mathrm{m}$. In order to scan 3D volumes a series of 2D images from different angels were made and afterwards reconstructed by the software YXLON Recoonspooler Workspace 1.4.4.0. The reconstructed volume was transferred to the VG Studio MAX 3.3.4 software. In order to analyse the volume correctly, an optimisation must be performed before further investigation. In Figure $2 \mathrm{a}$ a reconstructed volume and in Figure $2 \mathrm{~b}$ its respective grayscale histogram are presented. If the threshold and/or the brightness is not optimised, a falsification of the analysis is most likely possible, due to poor contrast between material and defects. By changing the light-blue line in the histogram (see Figure $2 b, d$ ), the contrast between defects (or background) and the specimen can be influenced. In addition, the brightness of the specimens can be differed in an attempted to increase the contrast between defects and specimen. In Figure $2 b$, the greyscale histogram of the scanned specimen as scanned is shown. Compared to that, in Figure $2 \mathrm{~d}$ an adjustment of the light-blue line was applied, and therefore the contrast and brightness settings are changed. The impact of these changes can be compared in Figure 2a,c. Furthermore, if the background colour is changed to the 
colour black the contrast is increased. From the results, it is clear that the contrast and brightness must be optimised to increase the detectability of internal defects.

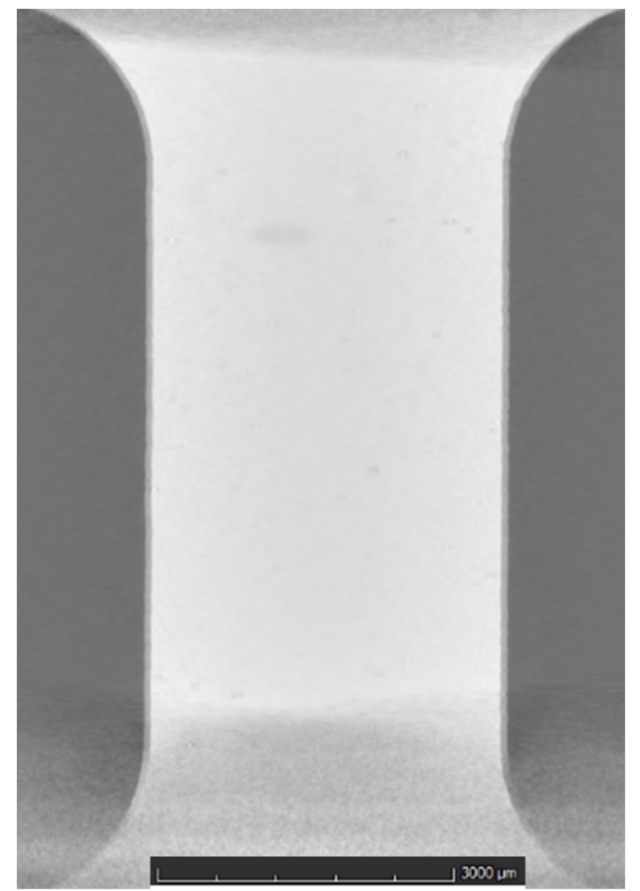

(a)

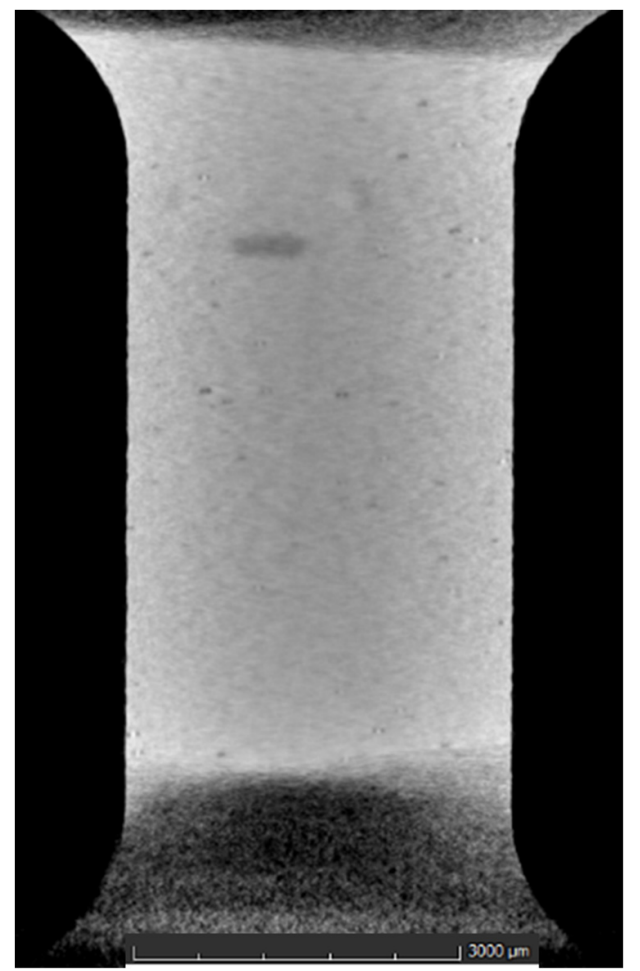

(c)

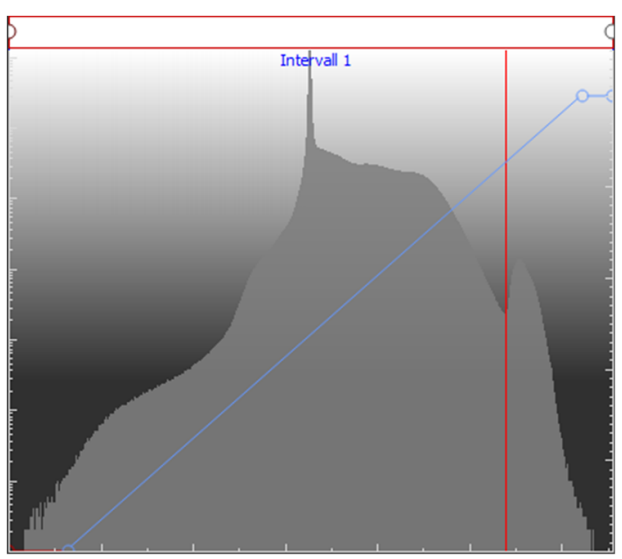

(b)

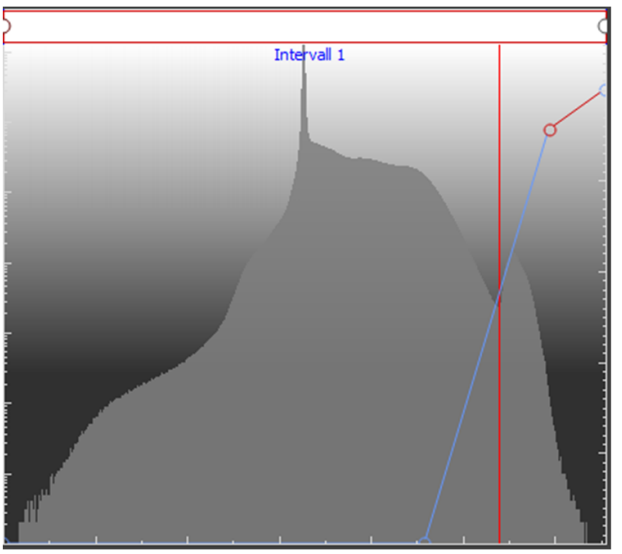

(d)

Figure 2. Different greyscale histograms and their respective influence on the scanned part: (a) reconstructed volume, as scanned, without any optimisation of brightness and contrast; (b) greyscale histogram for (a); (c) reconstructed volume with optimisation of brightness and contrast; and (d) greyscale histogram for (c). The histograms in (b,d) have the grayscale from 0-32000 (16-bit grayscale figure) as the $\mathrm{x}$-axis, and the logarithmic intensity is given as the $\mathrm{y}$-axis. 
Defects affect the mechanical behaviour of load-bearing parts either due to notch effects, crack nucleation sights or, in extreme cases, load-bearing cross-section reduction [23]. In order to investigate the influence of defects a Deben CT5000 tensile test stage was used. The stage, see Figure 3, can operate in a tensile or pressure mode with a force of up to $5000 \mathrm{~N}$. For these measurements the sample geometry had to be designed in such a way that the maximum force of the tensile tests did not exceed $5 \mathrm{kN}$. Consequently, a small test cross-section and thin sample material must be used, see Figure 4 . In order to manufacture these tensile test specimens, three blocks with the dimensions of $40 \times 20 \times 120 \mathrm{~mm}$ were first EB-PBF-manufactured. Subsequently, the heat treatments (STA and BASCA) were performed on individual blocks; afterwards, the tensile test specimens, according to Figure 4, were shaped out of these blocks using an electro-erosive process as well as a laser cutter. Due to the extra energy transported into the specimens during the laser cutting an oxygen analysis using Elementar's inductar EL cube was conducted. It showed an insignificant oxygen pickup. In Figure 5 the microstructure of an in situ specimen after a laser cut can be seen. There is no oxygen pickup, and therefore no microstructural change ( $\alpha$-case) to be seen. Nevertheless, a roughening of the surface to a saw-like form is occurring. This can lead to micro-cracks and therefore greatly impact the mechanical performance.

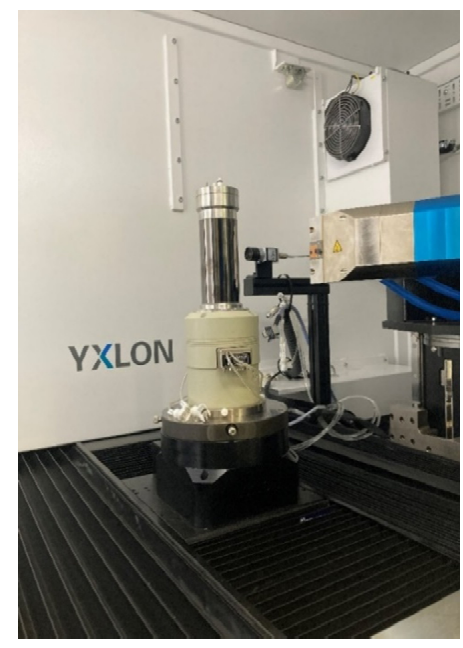

Figure 3. Deben CT5000.

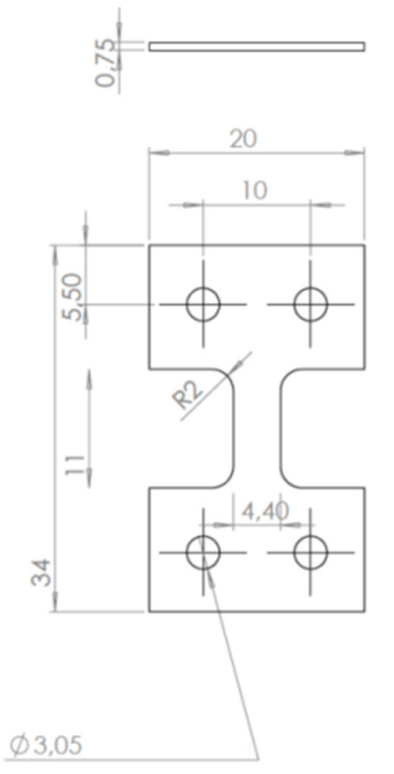

Figure 4. In situ tensile test specimen geometry. 


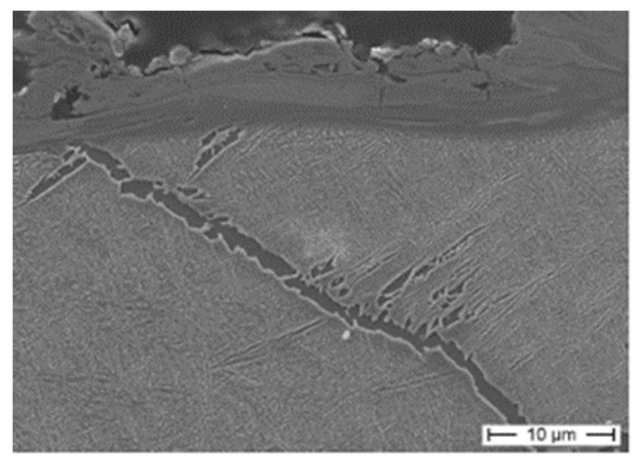

Figure 5. In situ specimen of a laser-cut EB-PBF-manufactured Ti-5553 alloy, SEM.

By using an in situ tensile stage it is possible to track failure relevant defects over the full time of a test. Hence, a load-dependent analysis of the defect behaviour can be made. The VGEasyPore algorithm of the software used was applied to analyse the reconstructed volumes for defects. A defect is defined as a region where the difference in the greyscale is large enough compared to the average. For this reason, it is of great importance that the brightness and contrast are optimised and standardised.

To determine the load levels of each heat-treated specimen, a conventional tensile test using the Deben stage was performed in advance for each of the geometries shown in Figure 4. In Figure 6, a schematic of a tensile elongation diagram can be seen. In order to minimise scanning time after one initial scan without any force, multiple scans were made $10 \%$ below and above the expected YS. Furthermore, at least two more scans were made until failure in order to monitor the morphology change in the defects. This was done because otherwise important information on the defect morphology would have been lost. During the complete tensile/scanning process shown in Figure 6 the stage and specimens remained inside the $\mathrm{CT}$, and therefore it can be assumed that all pictures were taken from the same position. For each heat treatment condition, a total of three in situ tensile tests were performed.

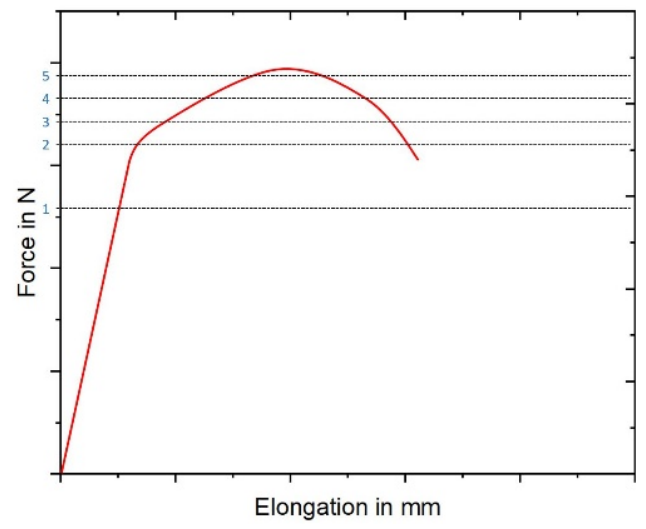

Figure 6. Schematic force/elongation diagram with required scans (vertical lines numbered from $1-5)$ next to the initial scan.

The conventional tensile tests were carried out in a Zwick 1474 material tester, in accordance with DIN EN ISO 6892-1 [39], using a constant elongation rate of $0.55 \mathrm{~mm} / \mathrm{min}$. The specimens were machined out of EB-PBF-manufactured cylinders. The used geometry is shown in Figure 7. Three comparable specimens were conventionally tensile-tested for each investigated condition. 


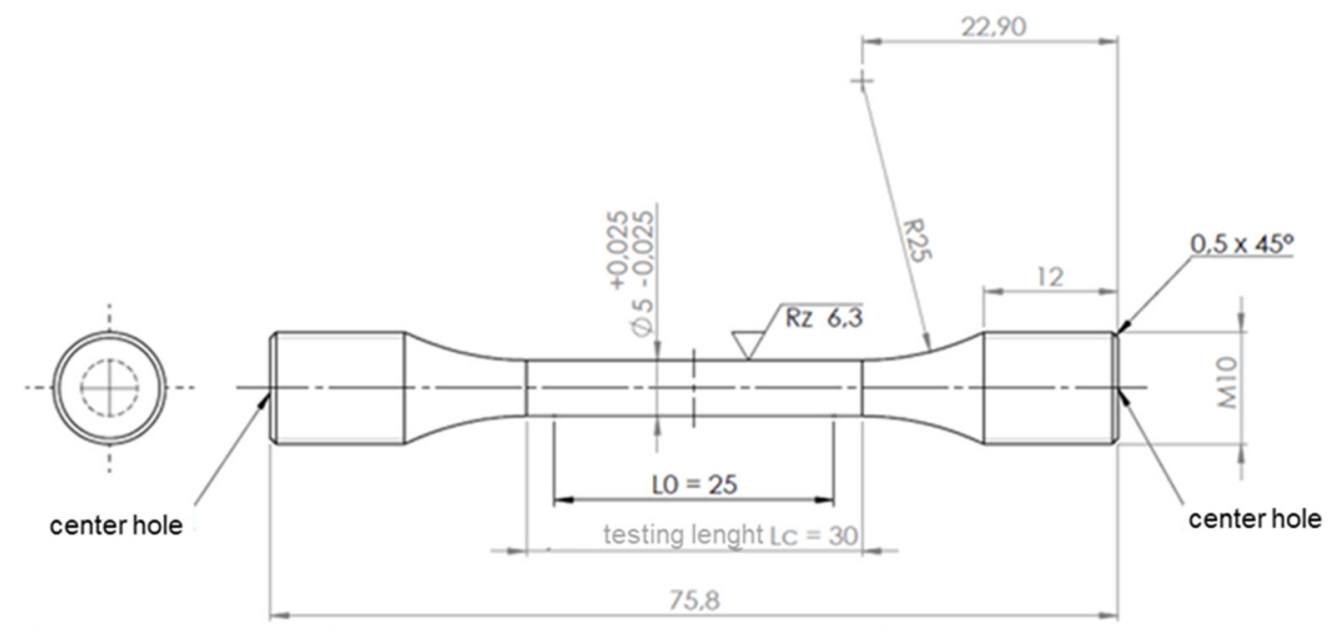

Figure 7. Conventional tensile test specimen geometry in accordance with DIN EN ISO 6892 [39].

\section{Results}

\subsection{Microstructure}

In Figure 8, the microstructures after the respective heat treatments are presented. The microstructure after the STA heat treatment is much finer and shows a smaller quantity of large $\alpha_{p}$, but more of fine $\alpha_{s}$, compared to the as-built microstructure. This can be seen by comparing Figure $8 a, b$ to Figure 1 . Due to the solution step below the $\beta$-transus temperature $\left(T_{\beta}\right)$, a large number of $\alpha$ nucleation sites are being introduced, and therefore a refining of the precipitations takes place. Furthermore, it can be seen that $\alpha_{p}$ precipitate either along grain boundaries or grow almost perpendicularly away from the grain boundary into the grains. In Figure 8, very fine precipitated $\alpha_{\mathrm{S}}$ can be seen. These precipitations are nucleated during the quenching, possibly at the metastable $\omega$ phase $[40,41]$, and can grow and rearrange during the aging step [29]. If these $\alpha_{s}$ precipitates are held for long times at high temperatures they form triangles [42], which appear to be superior for a high mechanical strength. The mechanical properties are shown in Table 2. Due to the fine precipitations, dislocations can be accumulated conveniently; moreover, hard precipitations show a different deformation behaviour than the surrounding matrix. Hence, a microstructure that leads to a high mechanical strength and low elongations was achieved. When comparing the STA microstructure in Figure 8a,b to the BASCA microstructure in Figure 8c,d, it can be seen that the precipitations are shaped differently. During the annealing step of the BASCA heat treatment, the as-built microstructure was completely dissolved and in the subsequent slow cooling $\alpha_{p}$ was precipitated. Due to the long times at high temperatures $\left(>600{ }^{\circ} \mathrm{C}\right.$ ), the quantity of large $\alpha_{\mathrm{p}}$ is very high. When the samples were held at $600{ }^{\circ} \mathrm{C}$ at the aging step $\alpha_{\mathrm{s}}$ can be precipitated inside the grains, and both ( $\alpha_{\mathrm{p}}$ as well as $\left.\alpha_{\mathrm{s}}\right)$ can grow into large precipitations.

Table 2. Comparison of conventional and in situ tensile test results of EB-PBF Ti-5553 using $\mathrm{E}_{\mathrm{L}}=600 \mathrm{~J} / \mathrm{m}$.

\begin{tabular}{cccc}
\hline Material State & YS in MPa & UTS in MPa & Elongation at Break in \% \\
\hline As-built $_{\text {con. }}$ & $860 \pm 0$ & $887 \pm 71$ & $21.90 \pm 2.9$ \\
As-built $_{\text {in situ }}$ & $820 \pm 3$ & $856 \pm 5$ & $1.1 \pm 0.2$ \\
STA $_{\text {con. }}$ & $1360 \pm 14$ & $1460 \pm 21$ & $4.2 \pm 1.3$ \\
STA $_{\text {in situ }}$ & $1166 \pm 42$ & $1212 \pm 41$ & $1.21 \pm 0.1$ \\
BASCA $_{\text {con. }}$ & $888 \pm 15$ & $971 \pm 13$ & $22.1 \pm 1.0$ \\
BASCA $_{\text {in situ }}$ & $881 \pm 2$ & $943 \pm 26$ & $1.32 \pm 0.4$ \\
\hline
\end{tabular}




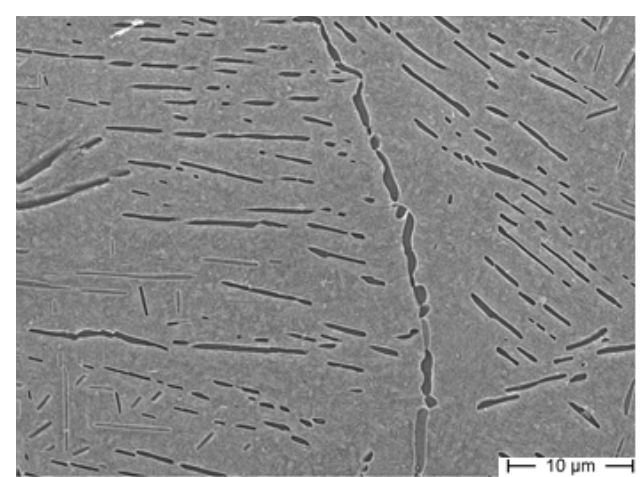

(a)

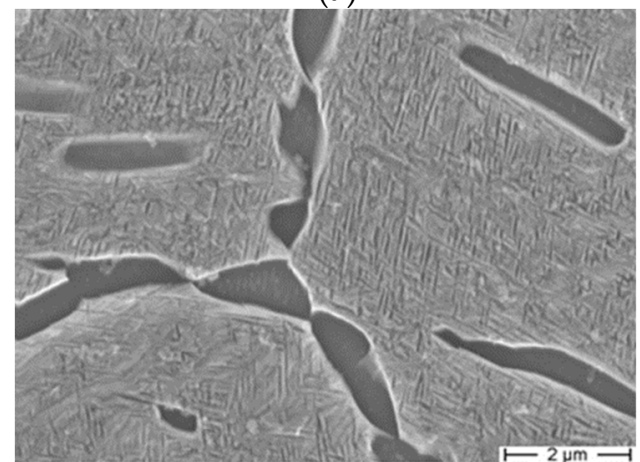

(b)

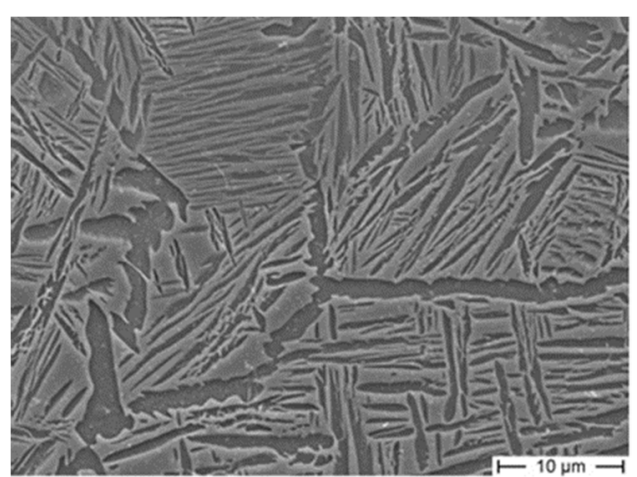

(c)

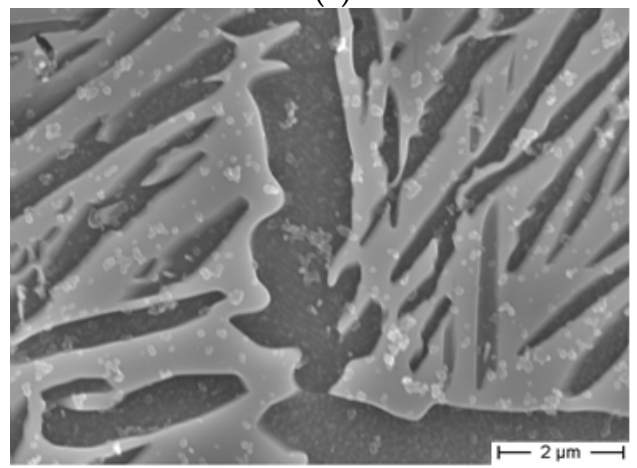

(d)

Figure 8. Different microstructures of an EB-PBF Ti-5553 alloy using $E_{\mathrm{L}}=600 \mathrm{~J} / \mathrm{m}$. (a,b): STA; (c,d): BASCA.

\subsection{Mechanical Properties}

In general, it can be said that heat treating the specimens leads to different mechanical properties. When using an STA heat treatment, the YS as well as the UTS rises by a large margin, and concurrently the elongation at the break decreases. By applying a BASCA heat treatment for the used geometry, the mechanical properties are, if standard deviations are taken into account, almost unaffected. There are, however, recognisable differences between the conventionally measured mechanical properties and the in situ properties. The YS and UTS are reduced by $1-17 \%$, but if standard deviations are considered they are very comparable. This notwithstanding, a large difference can be seen for the achieved elongations. The in situ specimens all failed after roughly a $1.2 \%$ elongation, which represents a great reduction compared to the conventionally tested samples. In contrast, the conventional test samples are manufactured via EB-PBF but tested on a Zwick 1474 according to the geometry shown in Figure 7.

In Figure 9 typical fracture surfaces for STA $(a, b)$ and BASCA $(c, d)$ heat-treated specimens can be seen. The possible deformation of the microstructure and therefore the fracture behaviour is dependent on the ratio of matrix-to-precipitations. The surface presented in Figure 9a shows almost no constriction, a slivery shine and a strongly structured surface. Hence, the specimens failed in a very brittle manner. Figure $9 b$ shows that the fracture pattern has areas of a ductile trans-crystalline honeycomb structure, but that it is mostly a brittle inter-crystalline structure. In comparison, the BASCA specimen, Figure 9c, shows a constriction and a smaller area where the specimen failed when the load-bearing cross section was too small. The higher magnification presented in Figure $9 \mathrm{~d}$ shows the typical trans-crystalline honeycomb structure pattern of ductile failure. 


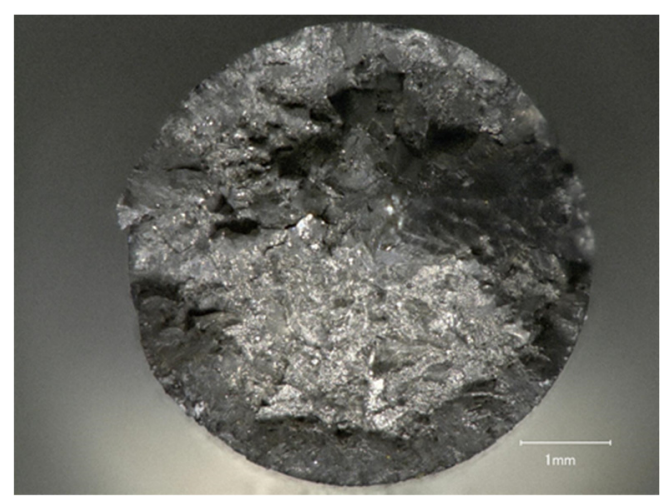

(a)

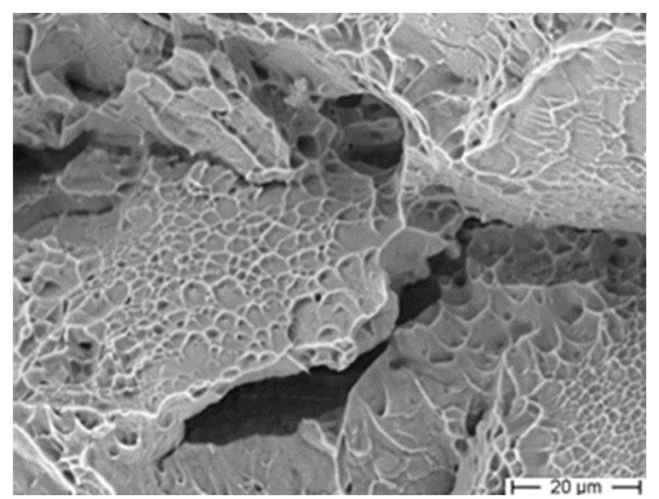

(b)

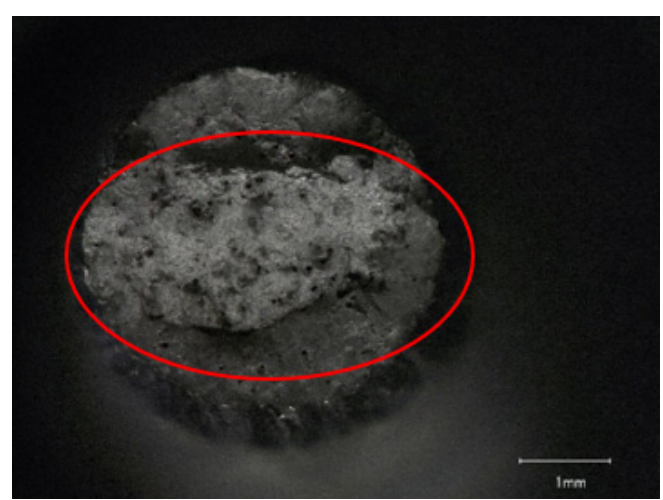

(c)

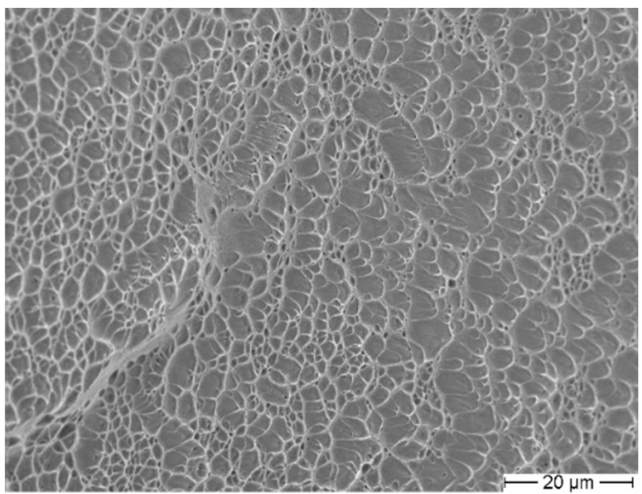

(d)

Figure 9. Different fracture surfaces of an EB-PBF-manufactured Ti-5553 alloy using $E_{L}=600 \mathrm{~J} / \mathrm{m}$. $(\mathbf{a}, \mathbf{b})$ : STA; $(\mathbf{c}, \mathbf{d})$ : BASCA. (a) as well as $(\mathbf{c})$ are overviews and $(\mathbf{b}, \mathbf{d})$ are close ups.

\subsection{Industrial Computer Tomography}

When analysing the $\mu$-CT scans, defects at different locations were detected. After YS was reached at a load level of $3700 \mathrm{~N}$, a surface defect was detected in one STA heattreated specimen (STA 1), see Figure 10. The specimen failed at $4000 \mathrm{~N}$ (1212 MPa), and it can be assumed that the failure started at the indicated location. For another STA heattreated specimen (STA 2), the possible internal failure-critical defect is shown in Figure 11. This figure shows two defects in close proximity after the final load level at $4100 \mathrm{~N}$ has been reached. No failure could be detected in this specimen, but a clear change in the force/elongation graph is visible. The defects displayed in the figures are only the failurecritical defects. Other smaller defects are located inside the specimens, but these do not have an influence on the material failure.

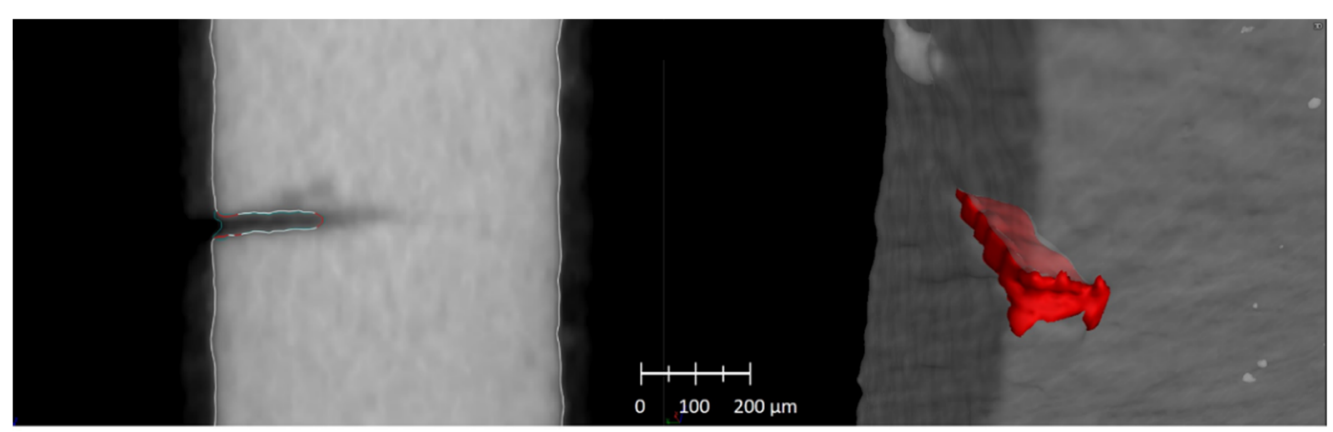

Figure 10. Failure-critical surface defect, marked in red, of an STA heat-treated EB-PBF-manufactured Ti-5553 alloy using $\mathrm{E}_{\mathrm{L}}=600 \mathrm{~J} / \mathrm{m}$. 


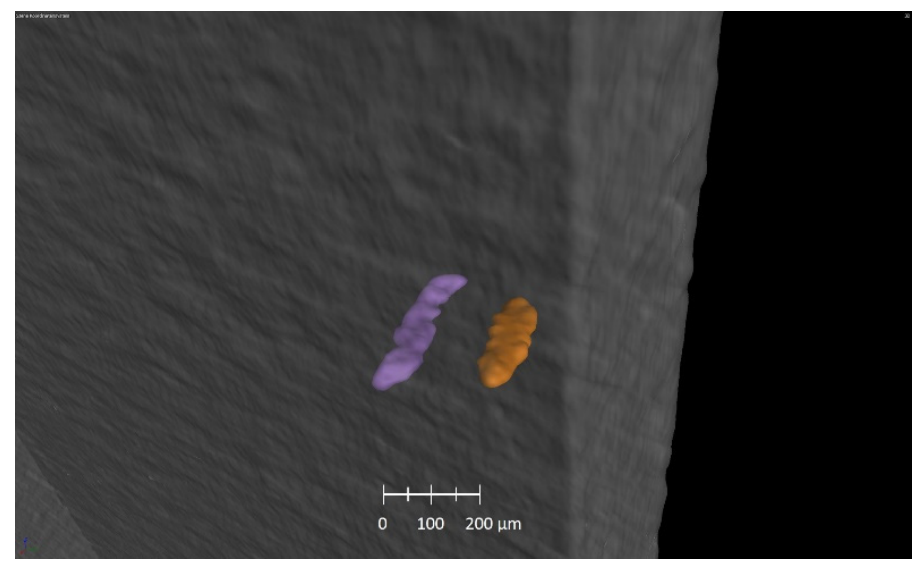

Figure 11. Failure-critical inner defects, purple and orange, of an STA heat-treated EB-PBFmanufactured Ti-5553 alloy using $\mathrm{E}_{\mathrm{L}}=600 \mathrm{~J} / \mathrm{m}$.

The force-elongation curves of the described STA and BASCA specimens can be seen in Figure 12. In the graphs of the two STA specimens it can be seen that these drop sharply after reaching the maximum applied force. This is an indication of specimen failure, as no further increase in force can be observed, despite a further increase in the jaw distance. In Figure 13 the correlation of the defect volume and the expansion along the $\mathrm{z}$-axis over the load level can be seen. The defects are located inside the specimens and do not have any connections to the surface. These show a constant increase in volume, but the expansion along the z-axis rises strongly for the highest load levels. The connection between load level and defect shape can be seen in Figure 14 (all figures of the defects were taken from the same angle and position).

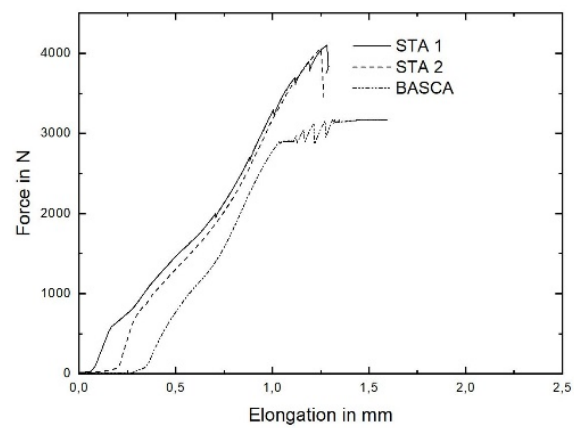

Figure 12. In situ force/elongation curves of heat-treated EB-PBF Ti-5553 alloy using EL $=600 \mathrm{~J} / \mathrm{m}$.

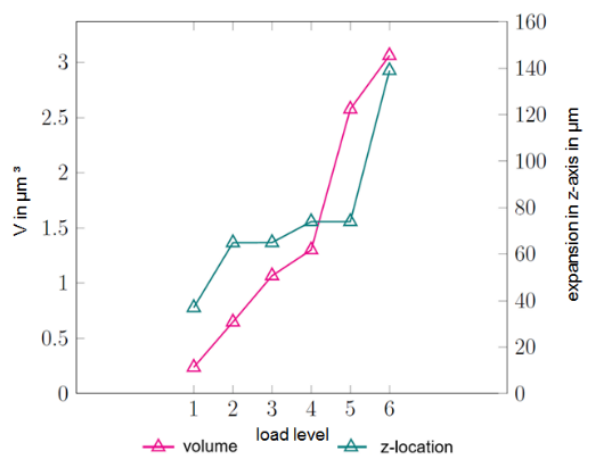

Figure 13. Geometrical change of a defect during in situ tensile testing of a BASCA heat-treated EB-PBF Ti 5553 alloy using EL $=600 \mathrm{~J} / \mathrm{m}$. 


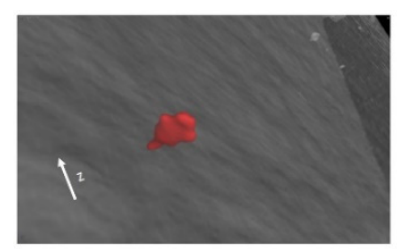

(a) load level 1

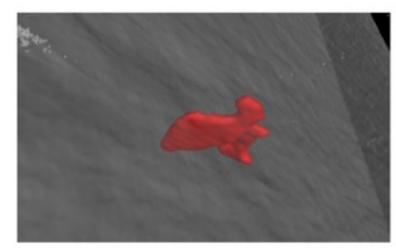

(d) load level 4

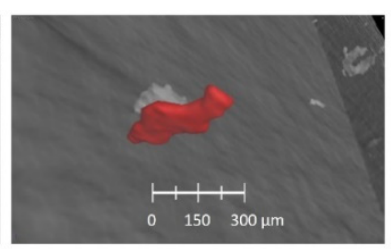

(b) load level 2

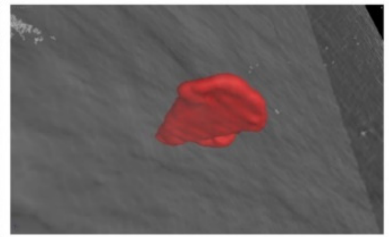

(e) load level 5

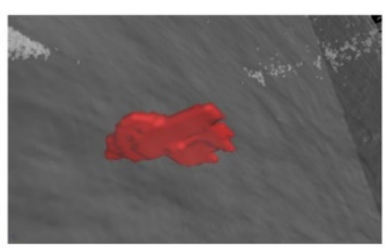

(c) load level 3

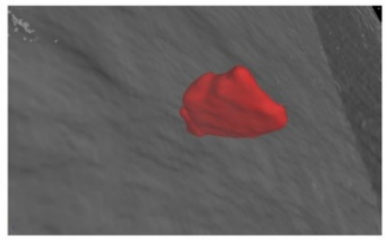

(f) load level 6

Figure 14. Change of the failure-critical defect, marked in red, of a BASCA heat-treated Ti-5553 alloy using $\mathrm{E}_{\mathrm{L}}=600 \mathrm{~J} / \mathrm{m}$. Load level: (a) $2900 \mathrm{~N}$, (b) $2975 \mathrm{~N}$, (c) $3050 \mathrm{~N}$, (d) $3125 \mathrm{~N}$, (e) $3155 \mathrm{~N}$ and (f) $3170 \mathrm{~N}$.

\section{Discussion}

\subsection{Microstructure-Mechanical Properties Correlation}

The results have shown that the microstructure and therefore mechanical properties can be tailor made. The STA heat-treated specimens show a high mechanical strength and low elongation at break. This is due to the small size and the needle shape of the $\alpha_{\mathrm{s}}$ precipitations formed during the short quenching and aging periods. At the solution step $\alpha_{\mathrm{p}}$ is dissolved. However, precipitates can grow during further heat treatment. Furthermore, it can be assumed that the temperature is not sufficient to completely dissolve the as-built microstructure during the solution step. Hence, a fraction of the original $\alpha_{\mathrm{s}}$ remains as part of the microstructure. $\alpha_{\mathrm{s}}$ precipitations can grow during the aging step, but due to the short dwell time $(60 \mathrm{~min})$ and relatively low temperatures $\left(500{ }^{\circ} \mathrm{C}\right)$ the needles remain small and their needle shape is preserved. These create, along with the $\beta$-matrix dislocation barriers, the very high mechanical strength and the low elongation at break. The achieved mechanical properties are comparable to conventionally produced and heat-treated Ti-5553 parts [11]. Other research groups show that by increasing the aging temperatures as well as the respective holding time the elongation at break can be enhanced, while the mechanical strength is decreased [15]. Compared to the STA heat treatment, the specimens heat-treated using the BASCA heat treatment show very good ductile properties and balanced mechanical strength-see Table 2 . Due to the high annealing temperature $\left(890^{\circ} \mathrm{C}\right)$ and long holding times (90 $\mathrm{min})$, it can be assumed that the as-built microstructure is completely dissolved. The more coarse primary and secondary $\alpha$ precipitations lead to very ductile properties due to the good deformability of the $\beta$-matrix and the slip, shear and twinning mechanisms of the precipitations. As shown in Table 2, the achieved elongations at break for the in situ tensile-tested specimens are very low.

\subsection{In Situ Tensile Testing}

The results indicate that the mechanical properties, especially the elongation at break for the in situ tensile test, are reduced dramatically compared to the conventional tensile tests. Since the microstructural constituents of the specimens for the in situ tensile test are identical to the microstructural constituents of the specimens used for the conventional tensile tests, as-built, STA and BASCA, the influences on the mechanical characteristic values obtained in the in situ tensile tests can only be attributed to the specimen geometry (see Figures 4 and 7) and the associated difficulties in mounting the specimens. Due to the use of a laser cutting step, the surface regions are rugged and defects that were previously on the inside will become defects close to the surface. Consequently, the surface quality is negatively affected. 
Furthermore, during the fabrication and mounting of the flat tensile specimens, some twisting or torsional loading of the specimens may have occurred. This also leads to multiaxial stress in the tensile test, which has a significant influence on the measured values.

The fracture mechanism of STA heat-treated specimens, which was discussed in Section 3.1, had a major influence on the in situ tests. The very brittle fracture, typical of mechanically highly stressable materials, limits the detection and monitoring of failurecritical defects at early load stages. The first cracks were detected shortly after reaching the YS, suggesting that the strength differences between the hardened matrix and the softer $\alpha_{p}$ precipitates, mainly along the grain boundaries (see Figure $8 \mathrm{a}, \mathrm{b}$ ), were too large. Such a structural arrangement can lead to premature crack nucleation [13,43]. Furthermore, surface defects, see Figure 10, are regions of high stress concentration, and these can also reduce the mechanical strength [44]. The combination of highly stressed surface defects with brittle material properties and very thin test geometries can lead to a significant influence of notch effects related to these defects, and thus early failure. Inside the second STA specimen tested in situ (see Figure 10), two defects were identified which were in close proximity to each other and to the surface. Consequently, the resulting test cross-section was reduced and thus the range of the stress distribution was very small. This caused the specimens to fail at lower stress and strain levels. It was possible to detect the failure-critical defect of the specimens following the in situ CT analyses made for each load level. The graph in Figure 13 shows an almost constant growth in the defect volume, but only for the final load levels is a major growth along the $\mathrm{z}$-axis can be seen. In Figure 14e,f this fact is seen in the analysis of the $\mu-C T$ data. This could indicate that the shape change is finished due to geometrical instability despite the application of higher stresses. It can be assumed that the specimen fails because the change in shape of the defect and the plastic deformation of the material cannot compensate these higher stresses, and therefore cracks are nucleated. Hence, the tested specimen fails shortly after the stress is increased to the next level. With these small test sample geometries and their thin wall thicknesses, the ductility of the bcc $\beta$-phase is not sufficient to absorb the stresses during the tensile test. BASCA as well as STA heat-treated specimens fail at the boundary between the two present phases $(\alpha$ and $\beta$ ). Furthermore, defects for such small test object geometries have an increased (bad) influence, due to the bad defect-to-test-volume ratio, on the mechanical strength $[45,46]$

\section{Conclusions}

This work shows that the microstructure of fully dense AM EB-PBF Ti-5553 specimens can be adjusted in order to create tailored mechanical properties. By using an STA heat treatment, very high mechanical strength and good elongation can be achieved. When a BASCA heat treatment is applied, a microstructure that results in very ductile and good mechanical strength can be achieved. Other researchers have shown $[15,42]$ that the distribution of the two Ti phases found in Ti-5553 has a significant influence on the mechanical properties. The correlation of the mechanical strength with the achieved microstructure shows that the shape, size and distribution of $\alpha$ precipitations have a considerably large impact. Generally, large $\alpha_{\mathrm{p}}$ precipitations result in an increased elongation at break, whereas small needle-shaped $\alpha_{s}$ precipitations lead to very high mechanical strength and low elongation at break. If the precipitates are very large, more $\beta$-matrices can be found, which leads to very ductile and good fatigue properties. One main focus of this presented work was the implementation of tensile testing using a Deben CT5000 in an industrial $\mu$-CT YXLON ff35 CT. For this purpose, an appropriate specimen geometry was developed. In order to evaluate, analyse and monitor the failure-critical defects of the tested parts on the tensile stage, the scan parameters were optimised. Furthermore, strategies were developed and standardised for the optimisation of the grey scale and brightness of 3D reconstructed volumes, in order to improve the subsequent analysis. If new specimens are investigated, it must be mentioned that the same specimen geometries as well as $\mu$-CT parameters should be used, in order to be able to compare the results. In situ tests and analyses were made 
for specimens processed with each heat treatment. For each sample the failure-critical defect(s) was found. Conclusively it can be said, for conventionally tested specimens, that the defects have a minor influence on the static mechanical properties. Regarding the small specimens used for the in situ tensile test, the defects can have a major influence on the mechanical properties. The main difference when comparing conventional and in situ tensile test results is that the defect-to-test-volume ratio is much worse for the in situ specimens. This effect is even worse when the defects are located at/close to the surface, and thus great stress concertation occurs. Moreover, it should be mentioned that the cuboid tensile specimen cross-section used in the in situ tensile test can also have a significant influence on the mechanical properties obtained. Furthermore, it was possible to monitor defects during every load level for BASCA heat-treated specimens. In contrast to the almost constant volume growth of the defects, it was observed that just before failure the failure-critical defect showed a major growth in the direction of the z-axis (in this setup, the direction of deformation). It has been found that this effect is used as an indicator for the failure-critical evaluation of the respective defect. It should be noted that for materials which have more ductile properties the defect monitoring is much better. Materials that fail in a ductile manner show a detectable defect growth compared to materials that fail in a brittle manner. Conclusively, it can be said that when the area of stress distribution is small, a more critical evaluation of defects regarding their influence on the mechanical strength must be made. If materials fail in a brittle manner, that effect is enhanced. For further investigations, it will be necessary to develop a new tensile specimen geometry and also change the cutting technology due to the rough surface of the specimens. Due to the AM of the specimens using the EB-PBF process, it can be assumed that the defects inherent in the process are evenly distributed in the components. In order to be able to make a more reliable statement on the failure-critical defects, the number of specimens must be increased in further tests.

Author Contributions: J.H. and A.M.; methodology, J.H., S.D. and A.M.; validation, J.H., S.D. and A.M.; formal analysis, J.H. and S.D.; investigation, J.H. and S.D.; resources, L.S., E.L., F.B. and C.L.; data curation, J.H. and S.D.; writing-original draft preparation, J.H.; writing-review and editing, A.M. and C.L.; visualisation, J.H. and S.D.; supervision, A.M. and C.L.; project administration, A.M. and C.L.; funding acquisition, L.S., E.L., F.B. and C.L. All authors have read and agreed to the published version of the manuscript.

Funding: The authors would like to thank the BMBF (Bundesministerium für Bildung und Forschung) for the financial support within the "AGENT-3D_QualiPro" project (funding code 03ZZ0212G).

Conflicts of Interest: The authors declare no conflict of interest.

\section{References}

1. Wilke, S. 'Umweltbewusstsein und Umweltverhalten', Umweltbundesamt. 4 July 2013. Available online: https://www. umweltbundesamt.de/daten/private-haushalte-konsum/umweltbewusstsein-umweltverhalten (accessed on 19 August 2021).

2. Willner, R.; Lender, S.; Ihl, A.; Wilsnack, C.; Gruber, S.; Brandão, A.; Pambaguian, L.; Riede, M.; López, E.; Brueckner, F.; et al. Potential and challenges of additive manufacturing for topology optimized spacecraft structures. J. Laser Appl. 2020, $32,032012$. [CrossRef]

3. Ramadani, R.; Belsak, A.; Kegl, M.; Predan, J.; Pehan, S. Topology Optimization Based Design of Lightweight and Low Vibration Gear Bodies. Int. J. Simul. Model. 2018, 17, 92-104. [CrossRef]

4. Seabra, M.; Azevedo, J.; Araújo, A.; Reis, L.; Pinto, E.; Alves, N.; Santos, R.; Mortágua, J.P. Selective laser melting (SLM) and topology optimization for lighter aerospace componentes. Procedia Struct. Integr. 2016, 1, 289-296. [CrossRef]

5. Emmelmann, C.; Petersen, M.; Kranz, J.; Wycisk, E. Bionic Lightweight Design by Laser Additive Manufacturing (LAM) for Aircraft Industry; SPIE Eco-Photonics: Strasbourg, France, 2011; p. 80650L. [CrossRef]

6. Khajavi, S.H.; Partanen, J.; Holmström, J. Additive manufacturing in the spare parts supply chain. Comput. Ind. $2014,65,50-63$. [CrossRef]

7. Herzog, D.; Seyda, V.; Wycisk, E.; Emmelmann, C. Additive manufacturing of metals. Acta Mater. 2016, 117, 371-392. [CrossRef]

8. Uriondo, A.; Esperon-Miguez, M.; Perinpanayagam, S. The present and future of additive manufacturing in the aerospace sector: A review of important aspects. Proc. Inst. Mech. Eng. Part G J. Aerosp. Eng. 2015, 229, 2132-2147. [CrossRef]

9. DebRoy, T.; Wei, H.; Zuback, J.; Mukherjee, T.; Elmer, J.; Milewski, J.; Beese, A.; Wilson-Heid, A.; De, A.; Zhang, W. Additive manufacturing of metallic components-Process, structure and properties. Prog. Mater. Sci. 2018, 92, 112-224. [CrossRef] 
10. Antunes, R.A.; Salvador, C.A.F.; De Oliveira, M.C.L. Materials Selection of Optimized Titanium Alloys for Aircraft Applications. Mater. Res. 2018, 21. [CrossRef]

11. Panza-Giosa, R. Mechanical Properties of Heat treated Ti-5Al-5V-5Mo-3Cr-An Attempt to Define Critical Properties of Various Microstructural Features. In Proceedings of the ITA Titanium Conference, Las Vegas, NV, USA, 8 April 2008 ; p. 35.

12. Nyakana, S.L.; Fanning, J.C.; Boyer, R.R. 'Quick Reference Guide for_ Titanium Alloys in the 00s'. J. Mater. Eng. Perform. 2005, 14, 799-811. [CrossRef]

13. Leyens, C.; Peters, M. (Eds.) Titanium and Titanium Alloys: Fundamentals and Applications; Wiley-VCH Verlag GmbH \& Co. KGaA: Weinheim, Germany, 2003. [CrossRef]

14. Lütjering, G.; Williams, J.C. Titanium, 2rd ed.; Springer: Berlin/Heidelberg, Germany, 2007.

15. Sadeghpour, S.; Abbasi, S.; Morakabati, M.; Bruschi, S. Correlation between alpha phase morphology and tensile properties of a new beta titanium alloy. Mater. Des. 2017, 121, 24-35. [CrossRef]

16. Azizi, H.; Zurob, H.; Bose, B.; Ghiaasiaan, S.R.; Wang, X.; Coulson, S.; Duz, V.; Phillion, A. Additive manufacturing of a novel Ti-Al-V-Fe alloy using selective laser melting. Addit. Manuf. 2018, 21, 529-535. [CrossRef]

17. Zheng, Y.; Williams, R.E.; Sosa, J.M.; Wang, Y.; Banerjee, R.; Fraser, H.L. The role of the $\omega$ phase on the non-classical precipitation of the $\alpha$ phase in metastable $\beta$-titanium alloys. Scr. Mater. 2016, 111, 81-84. [CrossRef]

18. Rodrigues, M.C.; Garcin, T.; Militzer, M. In-situ measurement of $\alpha$ formation kinetics in a metastable $\beta$ Ti-5553 alloy using laser ultrasonics. J. Alloy. Compd. 2021, 866, 158954. [CrossRef]

19. Nag, S.; Banerjee, R.; Srinivasan, R.; Hwang, J.; Harper, M.; Fraser, H. $w$-Assisted nucleation and growth of $\alpha$ precipitates in the Ti-5Al-5Mo-5V-3Cr-0.5Fe $\beta$ titanium alloy. Acta Mater. 2009, 57, 2136-2147. [CrossRef]

20. Hendl, J. Gefüge-Eigenschaftsbeziehung einer Ti-5Al-5Mo-5V-3Cr Legierung Hergestellt Mittels Selektiven Elektronenstrahlschmelzen; Technische Universität Dresden: Dresden, Germany, 2018.

21. Huang, C.; Zhao, Y.; Xin, S.; Zhou, W.; Li, Q.; Zeng, W. Effect of microstructure on tensile properties of Ti-5Al-5Mo-5V-3Cr-1Zr alloy. J. Alloy. Compd. 2017, 693, 582-591. [CrossRef]

22. Li, C.-L.; Mi, X.-J.; Ye, W.-J.; Hui, S.-X.; Yu, Y.; Wang, W.-Q. Effect of solution temperature on microstructures and tensile properties of high strength Ti-6Cr-5Mo-5V-4Al alloy. Mater. Sci. Eng. A 2013, 578, 103-109. [CrossRef]

23. Yadollahi, A.; Shamsaei, N. Additive manufacturing of fatigue resistant materials: Challenges and opportunities. Int. J. Fatigue 2017, 98, 14-31. [CrossRef]

24. Sun, Y.; Huang, B.; Puleo, D.; Jawahir, I. Enhanced Machinability of Ti-5553 Alloy from Cryogenic Machining: Comparison with MQL and Flood-cooled Machining and Modeling. Procedia CIRP 2015, 31, 477-482. [CrossRef]

25. GKN Powder Materials. 2019. Available online: https://www.gknpm.com/globalassets/downloads/additive-manufacturing/ datasheets-am-materials/datasheets---titanium-alloys/ancoram-ti-5553.pdf/ (accessed on 23 August 2021).

26. TAG. Available online: https://www.tag.it/de/titanlegierungen-die-klassifizierung-teil-2/5/ (accessed on 23 December 2019).

27. Zopp, C.; Blümer, S.; Schubert, F.; Kroll, L. Processing of a metastable titanium alloy (Ti-5553) by selective laser melting. Ain Shams Eng. J. 2017, 8, 475-479. [CrossRef]

28. Schatt, W.; Blumenauer, H. (Eds.) Werkstoffwissenschaft, 8th ed.; Dt. Verl. für Grundstoffindustrie: Stuttgart, Germany, 1996.

29. Jones, N.; Dashwood, R.; Jackson, M.; Dye, D. $\beta$ Phase decomposition in Ti-5Al-5Mo-5V-3Cr. Acta Mater. 2009, 57, 3830-3839. [CrossRef]

30. Shekhar, S.; Sarkar, R.; Kar, S.K.; Bhattacharjee, A. Effect of solution treatment and aging on microstructure and tensile properties of high strength $\beta$ titanium alloy, Ti-5Al-5V-5Mo-3Cr. Mater. Des. 2014, 66, 596-610. [CrossRef]

31. Kar, S.K.; Ghosh, A.; Fulzele, N.; Bhattacharjee, A. Quantitative microstructural characterization of a near beta Ti alloy, Ti-5553 under different processing conditions. Mater. Charact. 2013, 81, 37-48. [CrossRef]

32. Ghosh, A.; Sivaprasad, S.; Bhattacharjee, A.; Kar, S.K. Microstructure-fracture toughness correlation in an aircraft structural component alloy Ti-5Al-5V-5Mo-3Cr. Mater. Sci. Eng. A 2013, 568, 61-67. [CrossRef]

33. Baudana, G.; Biamino, S.; Klöden, B.; Kirchner, A.; Weißgärber, T.; Kieback, B.; Pavese, M.; Ugues, D.; Fino, P.; Badini, C. Electron Beam Melting of Ti-48Al-2Nb-0.7Cr-0.3Si: Feasibility investigation. Intermetallics 2016, 73, 43-49. [CrossRef]

34. Fatemi, A.; Molaei, R.; Simsiriwong, J.; Sanaei, N.; Pegues, J.; Torries, B.; Phan, N.; Shamsaei, N. Fatigue behaviour of additive manufactured materials: An overview of some recent experimental studies on Ti-6Al-4V considering various processing and loading direction effects. Fatigue Fract. Eng. Mater. Struct. 2019, 42, 991-1009. [CrossRef]

35. Masuo, H. Influence of defects, surface roughness and HIP on the fatigue strength of Ti-6Al-4V manufactured by additive manufacturing. Int. J. Fatigue 2018, 117, 163-179. [CrossRef]

36. Carter, L.N.; Attallah, M.M.; Reed, R.C. Laser Powder Bed Fabrication of Nickel-Base Superalloys: Influence of Parameters. Superalloys 2012, 2012, 2826-2834.

37. King, W.E.; Barth, H.D.; Castillo, V.M.; Gallegos, G.F.; Gibbs, J.; Hahn, D.E.; Kamath, C.; Rubenchik, A.M. Observation of keyhole-mode laser melting in laser powder-bed fusion additive manufacturing. J. Mater. Process. Technol. 2014, 214, $2915-2925$. [CrossRef]

38. Bauch, J.; Rosenkranz, R. Physikalische Werkstoffdiagnostik; Springer: Berlin, Germany, 2017. [CrossRef]

39. DIN Deutsches Institut für Normung e. V. DIN EN ISO 6892-1; Beuth Verlag: Berlin, Germany, 2016.

40. Clément, N.; Lenain, A.; Jacques, P. Mechanical property optimization via microstructural control of new metastable beta titanium alloys. JOM 2007, 59, 50-53. [CrossRef] 
41. Contrepois, Q.; Carton, M.; Lecomte-Beckers, J. Characterization of the $\beta$ Phase Decomposition in Ti-5Al-5Mo-5V-3Cr at Slow Heating Rates. Open J. Met. 2011, 1, 1-11. [CrossRef]

42. Dehghan-Manshadi, A.; Dippenaar, R.J. Development of $\alpha$-phase morphologies during low temperature isothermal heat treatment of a Ti-5Al-5Mo-5V-3Cr alloy. Mater. Sci. Eng. A 2010, 528, 1833-1839. [CrossRef]

43. Dogan, B.; Terlinde, G.; Schwalbe, K.-H. Effect of Yield Stress and Environment on Fatigue Crack Propagation of Aged ti-10v-2fe3al. In Proceedings of the Sixth World Conference on Titanium, Cannes, France, 6-9 June 1988.

44. Ammar, H.; Samuel, A.; Samuel, F. Porosity and the fatigue behavior of hypoeutectic and hypereutectic aluminum-silicon casting alloys. Int. J. Fatigue 2008, 30, 1024-1035. [CrossRef]

45. Crupi, V.; Kara, E.; Epasto, G.; Guglielmino, E.; Aykul, H. Static behavior of lattice structures produced via direct metal laser sintering technology. Mater. Des. 2017, 135, 246-256. [CrossRef]

46. Leuders, S.; Thöne, M.; Riemer, A.; Niendorf, T.; Tröster, T.; Richard, H.; Maier, H. On the mechanical behaviour of titanium alloy TiAl6V4 manufactured by selective laser melting: Fatigue resistance and crack growth performance. Int. J. Fatigue 2013, 48, 300-307. [CrossRef] 